\title{
USING SCENARIOS TO INVESTIGATE STAKEHOLDERS' VIEWS ON THE FUTURE OF A SPORTING EVENT
}

\author{
MIGUEL MOITAL, CAROLINE JACKSON, AND JENNA LE COUILLARD \\ School of Tourism, Bournemouth University, Poole, UK
}

\begin{abstract}
The aim of this research was to identify if the continuation of a sporting event was supported by its stakeholders and what their objectives were for its future. Using a methodology adapted from scenario planning, the research investigated if the stakeholders desired the event to grow, and if so, in which areas and to what level. The finding was that the stakeholders supported its growth. They viewed the sporting event as being a small-scale to medium-scale event and saw it growing to become a medium- to large-scale event. A key finding was that the stakeholders had conflicting views about its future features, and this was due to their varying backgrounds and objectives set for the event. The results of this research emphasize the need for both researchers and practitioners to be more fully aware of the similarities and differences in stakeholder objectives in a dynamic, rather than static, environment.
\end{abstract}

Key words: Stakeholder; Growth; Scenarios; Community events; Sporting events

Introduction

The development of many event initiatives relies heavily on their ability to bring together resources from different stakeholders, whether volunteers, residents, local businesses, active participants, sponsors, police, fire brigade, councils, and ministries (Getz, 2008; Getz, Andersson, \& Carlsen, 2010; Larson, 2009). According to Crespi-Valbona and Richards (2007), a key factor leading to event success is the ability to persuade these stakeholders to get involved. Unlike commercial firms, resource exchange with several of these stakeholders involves neither a hierarchical nor a commercial relationship (Larson, 2009). Many stakeholders are willing to get involved and contribute to the production of the event not because of the opportunity to trade goods or services for monetary value but because of other benefits (Toor \& Ogunlana, 2010). These benefits include enhanced pride, skills and knowledge, self-esteem, reputation, and power for those involved, whether individuals or organizations (Buch, Milne, \& Dickson, 2011; Getz \& Andersson, 2009; Larson, 2009). In addition, it is not uncommon for the interests of some of these stakeholders to be antagonistic (Karlsen \& Nordström, 2009; Toor \& 
Ogunlana, 2010), leading to potential conflict (Larson \& Wikström, 2001; Reid, 2011), which if not properly managed can affect the running of the event. There are plenty of examples (e.g., CityLocal, 2009; Cymbalista-Clapp, 2011; Endley, 2011) where the growth and expansion of events has been hampered by the opposition of specific stakeholders. In extreme cases of conflict, extinction of the event can take place.

Deciding on the future of an event becomes more complex when one accepts Larson and Wikström's (2001) "political market square” analogy that rejects "the notion of the organization as an independent actor that can produce events, and by depicting it as a dependent co-producer... within a network of organizations and other stakeholder groups" (Getz, Andersson, \& Larson, 2007, p. 104). While effective stakeholder management is a vital ingredient of the management of any organization (Fletcher, Guthrie, Steane, Roos, \& Pike, 2003; Wheeler \& Sillanpaa, 1997), it takes on an even greater importance in the context of managing event initiatives (Reid, 2011). To date, few studies have looked at the management of events using stakeholder theory. Existing studies tend to adopt a retrospective perspective-looking at something that has happened or is happening (e.g., Buch et al., 2011; Karlsen \& Nordström, 2009) rather than a prospective one (looking into the future).

Ferrand and McCarthy (2009) take an interesting relationship marketing approach to sports organizations and their stakeholders (and therefore, implicitly, sports events). They identify that most sports are, by their nature, part of the community and rely upon a plethora of stakeholders for the sport itself to exist, whether it is the need for a public venue or a governing body that stipulates the rules and regulations that have to be adhered to. As providers of resources, an event's long-term survival is dependent on the willingness of its stakeholders to allocate those resources to the event. Reid (2011) has recently emphasized that competitive advantage through stakeholder support can only be achieved by reviewing "their agendas [which] will assist event managers in balancing the competing needs, tensions and expectations of all stakeholders” (p. 22). Using theories that have been developed to better understand the firm in society, notably scenario planning and stakeholder theory, this research attempted to further develop the application of stakeholder theory and to do this in an area that had been little explored, the dynamic nature of organizational growth in the field of events. It did this by examining the future of a sporting event by asking whether and how this event should continue to develop over the succeeding 3 years.

The research focused on one sporting event, a marathon, held on an island in Europe and organized by its main sponsor with support from a group of "enthusiastic volunteers." This is compared with most literature and models on stakeholders that assume there is one organization and a manager at the nexus of a network of relationships (Ferrand \& McCarthy, 2009; Karlsen \& Nordström, 2009; Mitchell, Agle, \& Wood, 1997). In the research case, it was two people in a non-events organization running the event and making decisions on its future. The event had proven to be a success, but decisions had to be made about its future size and component activities. The aim of the research was to examine the future of the event as perceived by its stakeholders. The following two objectives were defined:

- to investigate whether the event should continue to be organized or not and why;

- to examine the extent to which the event should grow and the nature of this growth for the next 3 years.

\section{Literature Review}

Stakeholder theory has been conceptualized over the past few decades, but little has actually been applied in practice and rarely to the organization of an event. Stakeholder authors have focused on four main facets of the theory: descriptive accuracy, normative theory of stakeholder identification, understanding instrumental power, and finally the managerial issues (Ferrand \& McCarthy, 2009; Friedman \& Miles, 2002; Mitchell et al., 1997). These will be further discussed below.

\section{Descriptive Accuracy}

As identified by Freeman (1984), one has to, first of all, identify and describe who the stakeholders are, so one has to define what they are. In an event's 
context, Goldblatt and Nelson (2001) and Bowdin, Allen, O’Toole, Harris, and McDonnell (2008) say that stakeholders are "people and organisations with a legitimate interest in the outcomes of an event" (p. 230). A similar definition is offered by Reid and Arcodia (2002), who define event stakeholders as individuals or groups that are affected or could be affected by the existing event. So, as Goldblatt (2008) says: "A stakeholder does not have to invest money in an event to be considered for this role. Emotional, political, or personal interest in a cause is evidence of investment in an event” (p. 14). One therefore has to identify what their "stake" is in the event, because this would help to devise strategies aimed at fostering support and avoiding opposition (Westerbeek et al., 2006). A broad or a narrow definition of stakeholders can be taken; in this research, the latter was taken, whereby only those that could affect the organization's strategic objectives were considered (Ferrand \& McCarthy, 2009; Mitchell et al., 1997).

\section{Normative Theory of Stakeholder Identification}

As the term describes, using "norm" references to identify who stakeholders are is based on what is currently acceptable in society, and therefore, this area has an ethical context. It is recognized by Ferrand and McCarthy (2009) that stakeholder and corporate social responsibility have the same theoretical roots. They state that it is "an organisation's duty to define and take into account the philosophical and moral frameworks in which it operates" (p. 31). Ryan (2002) argued that the adoption of sustainable practices, an imperative in the 21st century, required broadening the range of stakeholders that should be involved in decision-making. An event organization is, therefore, not operating responsibly if it does not take a positive position in identifying all stakeholders, be it those that could benefit the organization like its funders or those that could offer resistance to the event such as local residents who could be adversely affected by the congestion and controls caused by the event.

\section{Instrumental Power}

Just identifying who potential stakeholders are is insufficient and not necessarily effective when considering them as part of the decision making. As identified by Mitchell et al. (1997), the power that stakeholders may have over the decisions an organization makes is relevant to how they treat and, therefore, manage their relationship with them. This is related to the instrumental performance feature of stakeholder theory identified by Ferrand and McCarthy (2009) and the relative performance of the network of stakeholders created to support, in their case, the sports organization. The power of stakeholders identified in the literature is focused more on how you manage the relationship of the organization with the power that the stakeholders have over the organization, rather than their intrinsic or extrinsic interest in the organization, in this case, the event itself. A local council, for example, if they had the responsibility for awarding event licenses or permitting access to space, would be in a powerful position, and therefore, as a stakeholder has instrumental power over the event.

Johnson, Scholes, and Whittington (2005) recognized both the power and influence of a stakeholder and created a power/interest matrix, which was employed in this research as part of the process to identify and select the stakeholders to interview. The power/interest matrix categorizes stakeholders with regard to the amount of interest they have in supporting or opposing a particular strategy and in relation to how much power they have over supporting or opposing the strategy (Johnson et al., 2005). In the context of this research, the "strategy" is the future direction of the sporting event. Depending on the quadrant that a stakeholder is assigned to, the matrix implies a prioritization of stakeholders and suggests the key management activities leading to an effective stakeholder management. The four quadrants are as follows: Minimal Effort (A), Keep Informed (B), Keep Satisfied (C), and Key Players (D) (see Fig. 1).

\section{Managerial Issues in Events Management}

This area of stakeholder theory focuses on how you manage the stakeholders for your own interest, and in the case of a community sports event, it is important to understand how and why they are involved. Larson and Getz have been the main researchers of stakeholder theory in the events field. They particularly focused on the dynamic growth and development of festival organizations by comparing festivals in Calgary and Sweden. Getz and 


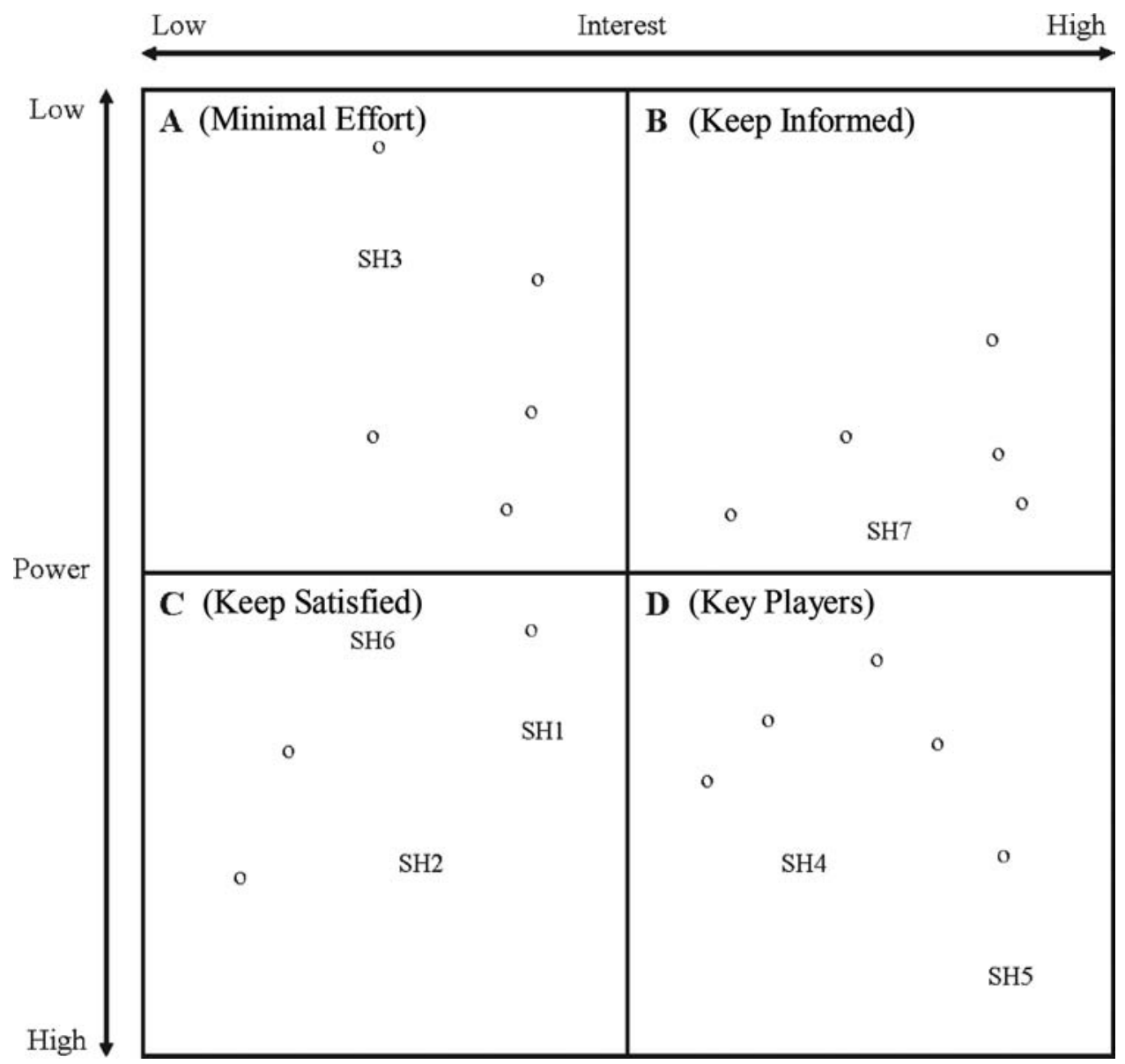

Figure 1. Power/interest matrix for the event. Dots and codes represent the various stakeholders of the event. The codes identify the seven stakeholders interviewed for this study.

Andersson (2009) conceptualized the development and maturity of festival organizations as the "institutionalization” and their acceptance, or legitimacy, of the event itself. They emphasized the importance of managing the many diverse stakeholder relationships within an event, with a view to developing a supportive network that could lead to a sustainable event. However, Getz et al. (2007) did not investigate how and whether stakeholders were directly engaged with the growth or demise of the festivals that they researched.

What is applicable to this research is how the events became "legitimate" (Getz et al., 2007) in terms of their acceptance to the community. This could be related to the rationale and objectives for the event and, therefore, whether the stakeholders even saw a future for the event and a development of an explanation as to why they would want it to continue. Ferrand and McCarthy (2009) contend that the strategic analysis should consider the objectives of stakeholders involved in the event, which may be economic, political, social, or environmental. This relates to the overall objectives for events, in general, of which there has been limited research. The main emphasis of research in this field has been predominantly focused on the impacts of events, which themselves are not objectives. The event must, therefore, take into account the desires and goals of the stakeholders. If one stakeholder perceived the event to not fulfill their own objectives, they could feel alienated, potentially leading to apathy or, in a more extreme case, to opposition to the event. This, in turn, influences the sustainability of the event, notably if the opposing stakeholder(s) are 
ones with large power and interest in the event. Ferrand and McCarthy's (2009) research is more about the nature of the relationship that is established between stakeholders. In contrast, this research is more interested in gathering stakeholders' views about the future of the event and what their personal objectives behind that view are.

Larson and Wikström (2001) explain that relationships can be understood from a consensus perspective and a conflict perspective. Reid (2011) argues that it depends on whether an event meets stakeholders' objectives, on whether they adopt a stance of support or opposition. The conflict perspective, associated with opposition, results from a different (and often incompatible) interest, leading to conflict and tension, power games, individual commitment, and distrust. Stakeholders have individual interests based on their commitment to achieving their goals. Conflict can occur when stakeholders' goals are inconsistent and when one stakeholder tries to stop the goal fulfillment of another stakeholder in order to increase their likelihood of achieving their goal (Larson \& Wikström, 2001; Reid, 2011).

Alternatively, the stakeholder would not use power games; they would trust each other, leading to cooperation instead (Larson \& Wikström, 2001). If they have the same view, which is mutual interest, then there should be harmony. Thus, the consensus perspective tends to foster support for the event. Mallen and Adams (2008) would identify this as the need for "collaborative individualism." The collaborative components of the concept emphasize the need for individuals to work together with a view to attain common objectives. The individual component stresses independence from the organization, the freedom to break from groups, organizations, and social institutions (Limerick, Cunnington, \& Crowther, 2002). This bringing together of individuals is, in essence, part of the stakeholder and network theory (Reid, 2011) and how they are managed (Mitchell et al., 1997).

In summary, there appears to be a belief that once the stakeholders are identified, different stakeholder experiences can be “managed” (Getz, 2007). However, as Getz recognizes, there are potential difficulties of getting stakeholder consensus on core values, which can lead to conflict. Managing conflict can be achieved by identifying ways to manage stakeholders' competing interests and goals
(Derrett, 2004). Reid (2011) found that appropriate strategies can be adopted to successfully manage these stakeholders' different objectives. However, for this to take place, it is important to understand what the stakeholders' objectives and goals are and how they should be met, which is what this research sought to address. By doing so, the forward thinking and strategic aspects are emphasized rather than the more operational ones, which involve the dayto-day management of the event. This is consistent with Ryan's (2002) claim that sustainable initiatives (including events) should result from a vision that is shared by the community of stakeholders.

\section{Methodology}

The review of the literature revealed very little stakeholder management research undertaken from a prospective point of view. Given the unavailability of a suitable methodology, Shoemaker's (1995) scenario planning process was used as the methodological underpinning. Scenario planning is a strategic management tool whereby businesses speculate about possible futures with a view to formulating strategies that could be implemented should one of these scenarios have concensus (Gummesson, 2000; Johnson et al., 2005; Yeoman \& McMahon-Beattie, 2005). This involves looking at external factors that could impact on the organization. However, while the scenario planning emphasizes the changes in the external environment that could affect the organization, the process for this research focused on where the event should be in the future as perceived by its stakeholders. Thus, the research process is centered on issues internal to the organization (i.e., the event). Despite this difference, much of the process put forward by Shoemaker (1995) is useful as a basis for designing a rigorous methodology for examining stakeholders' perceptions of the future of an event. The adaptation of Shoemaker's process resulted in the development of a six-stage process, which is described below.

\section{Stage 1: Defining the Scope}

The research focused on whether the event should continue to be organized or not, and if yes, whether its size and activities should be maintained or whether these should grow and the nature of this growth over the following 3 years. 


\section{Stage 2: Identifying Key Uncertainties and Constructing Initial Scenarios}

The key uncertainties that related to the event itself were identified. These were related to 3 years in the future of the event such as the number of participants that were desired in each race, the type of audience, and the features and activities included in the event. The analysis involved defining three types of event (small, medium, and large) and specifying the features of each type of event in relation to each key uncertainty (Table 1). In addition, stakeholders were presented with a table containing a range of actual and potential event features and asked how they felt about keeping/adding them in 3 years' time. In addition to the current race mix (marathon, relay race, and $3 k$ fun run), respondents were asked about the desirability of introducing other common running distances: $1 / 2$ marathon, $10 \mathrm{k}$, and $5 \mathrm{k}$. As far as the additional nonrace features are concerned, these included an exhibition, fairground rides, food and beverage stalls, a postevent party, as well as exercise classes and warm-up sessions. A 4-point Likert scale, reflecting the stakeholders' level of support for each feature, was employed ("definitely not," "probably not," "probably yes," "definitely yes”). There were also some open questions that mainly focused on probing the stakeholder as to why a certain answer was given. This allowed for a deeper understanding of the stakeholders' views.

\section{Stage 3: Validation of the Data Collection Instrument}

Validation began by reviewing whether the scenarios were consistent and plausible. Internal consistency could be checked by identifying whether the trends were compatible for the time frame. This involved asking, "are the aspects of the three different size events realistic in the 3 years' timeframe?" and "are the aspects of the small, medium, and large events consistent and plausible?" The answers to these were yes: The timeframe was appropriate (neither too short nor too long), there were clear differences between the three types of events, and the rise from small to medium to large was consistent.

A pilot study was conducted to ensure that the interview questions had been written appropriately

Table 1

Growth Scenarios

\begin{tabular}{|c|c|c|c|}
\hline Key Uncertainties & Small-Scale Event & Medium-Scale Event & Large-Scale Event \\
\hline Number of participants in the marathon & Under 1,000 & Under 5,000 & Under 8,000 \\
\hline $\begin{array}{l}\text { Number of participants in the relay race } \\
\text { (teams made up of five participants) }\end{array}$ & Under 1,000 & Under 5,000 & Under 8,000 \\
\hline Number of participants in the $3 \mathrm{k}$ fun run & Under 1,000 & Under 5,000 & Under 8,000 \\
\hline Participant mix in the marathon & $\begin{array}{l}\text { Majority are local } \\
\text { participants with a } \\
\text { few exceptions }\end{array}$ & $\begin{array}{l}\text { A mixture of local and } \\
\text { national participants }\end{array}$ & $\begin{array}{l}\text { A mixture of local, national, and } \\
\text { international participants }\end{array}$ \\
\hline Participant mix in the relay race & $\begin{array}{l}\text { Majority are local } \\
\text { participants with a } \\
\text { few exceptions }\end{array}$ & $\begin{array}{l}\text { A mixture of local and } \\
\text { national participants }\end{array}$ & $\begin{array}{l}\text { A mixture of local, national, and } \\
\text { international participants }\end{array}$ \\
\hline Participant mix in the $3 \mathrm{k}$ fun run & $\begin{array}{l}\text { Majority are local } \\
\text { participants with a } \\
\text { few exceptions }\end{array}$ & $\begin{array}{l}\text { A mixture of local and } \\
\text { national participants }\end{array}$ & $\begin{array}{l}\text { A mixture of local, national, and } \\
\text { international participants }\end{array}$ \\
\hline $\begin{array}{l}\text { Number of spectators physically present } \\
\text { on race day }\end{array}$ & Under 1,000 & Under 5,000 & Under 8,000 \\
\hline $\begin{array}{l}\text { Spectator mix physically present on } \\
\text { race day }\end{array}$ & $\begin{array}{l}\text { Local specta- } \\
\text { tors with a few } \\
\text { exceptions }\end{array}$ & $\begin{array}{l}\text { A mixture of local and } \\
\text { national spectators }\end{array}$ & $\begin{array}{l}\text { A mixture of local, national, and } \\
\text { international participants }\end{array}$ \\
\hline $\begin{array}{l}\text { Type of media coverage in terms of } \\
\text { television }\end{array}$ & Local TV coverage & $\begin{array}{l}\text { Local and national TV } \\
\text { coverage }\end{array}$ & $\begin{array}{l}\text { Local, national, and international } \\
\text { TV coverage }\end{array}$ \\
\hline Amount of prize money & Small amount, if any & Medium amount & Large amount \\
\hline Type of sponsor of events & Local sponsors & $\begin{array}{l}\text { Local and national } \\
\text { sponsors }\end{array}$ & $\begin{array}{l}\text { Local, national, and international } \\
\text { sponsors }\end{array}$ \\
\hline Level of community involvement & Low & Medium & High \\
\hline
\end{tabular}


to gain the required data (Jennings, 2001). The review of scenarios and the pilot study were carried out by the personal assistant of the race director who had been heavily involved in the organization of the event since the beginning. Only minor changes were made.

\section{Stage 4: Sample of Stakeholders}

Twenty-five stakeholders were identified as having an interest in the event. These were plotted on the power/interest matrix (Johnson et al., 2005), as seen in Figure 1. Both the identification and plotting of stakeholders were carried out initially by one of the researchers who worked on the event organization. This was then shown to the event director who reviewed it. As a result, one stakeholder was added, and the positioning of some of the plotted stakeholders changed, although minimally.

A total of seven stakeholders took part in the study, and their selection was based on three factors. First, the sample should be varied with regard to the type of stakeholder (Murphy et al., 2005), including representatives of an economic, political, operational, and consumer nature. Second, the sample should be relevant as given by the power/interest matrix. Priority was given to stakeholders with a high power and/or interest in the event. As shown in Figure 1, the majority of the seven stakeholders are located in Quadrants B, C, and D. One stakeholder from Quadrant A (local hospitality organization), where "minimal effort" stakeholders are located, was included. The decision was based on the fact that it was considered important to gain a perspective that represented a large part of the hospitality industry in the island. This study was positioned in the context of market development (Ansoff, 1956), which meant that, in order for the event to grow, new markets would need to be attracted. As the event is hosted on an island, this could mean attracting more people (participants and spectators) from outside the island. These people will come to the island and use the services of the local hospitality association members, so the more the event grows, the more affected this stakeholder group will be. The third and final factor influencing the choice of stakeholders was accessibility, meaning that a representative of the stakeholder should be easily identifiable and accessible. A brief description of each of the interviewed stakeholders is shown in Table 2.

\section{Stage 5: Data Collection: Interviews}

A semistructured face-to-face interview with some open-ended questions was employed to collect the data regarding the stakeholders' views of the future of the event. They were initially asked whether they thought the event should continue and why. They were then shown the scenario table (Table 1 ) to elicit their views on where they

Table 2

Profile of the Stakeholders Interviewed

Stakeholder

Profile and Explanation of Choice

SH1

SH2

SH3

SH4

SH5

SH6

SH7
This stakeholder is responsible for the provision and development of sport and leisure facilities and strategies in the region. It is also a member of the event's management committee.

In the island there are a number of parishes, and each has got a policing director. The route runs through the majority of the parishes so permission needs to be sought from these individuals to allow the route to run through their parish. One of these individuals has participated in the study.

This stakeholder is a trade association, which is involved with the hospitality industry in the island. It represents over 400 organizations from hotels to campsites to nightclubs to car hire companies.

This is an association that consists mainly of volunteers who provide a number of services in the community from road safety checks, to assisting the local police patrolling and marshalling at events. The President is also a member of the event's management committee.

This stakeholder is a representative of the title sponsor and organizer of the event. It is also a member of the event's management committee.

This stakeholder is representing the tourism industry. It has been involved with the event from the start and has been able to observe how the event has affected the tourism industry.

This stakeholder is a member of the event's management committee and represents the past runners of the event. 
currently perceived the event to be in terms of size and components and on what they would like the event to be in 3 years' time.

\section{Stage 6: Data Analysis}

The analysis was centered on the extent to which stakeholders shared a similar view on the future of the event as well as an attempt to understand the possible reasons for similarities and discrepancies. To facilitate the understanding of the results, some of the data were tabled to consolidate them, which allowed for emerging patterns to be recognized (Miles \& Huberman, 1994). Implicit in the tables summarizing some of the findings is a frequency analysis: How many people favored each type of event (small, medium, and large) or event feature? The open-ended question responses, such as why they wanted the event to continue, were initially analyzed using content analysis, and emerging themes were identified.

\section{Results and Discussion}

\section{Event Objectives}

The first question that stakeholders were asked was whether they would like the event to continue in the future or not. All respondents supported the continuation of the event. When asked about why they would like it to continue, a variety of reasons were expressed. As demonstrated in Table 3, where the $\mathrm{X}$ indicates an unsolicited stakeholder response, some emphasize the social aspect [e.g., Stakeholder 7 (SH7)], others mainly the economic benefits (SH3 and SH6), and others both the social and economic benefits (e.g., SH1 and SH2). This suggests that stakeholders may have different agendas and objectives for supporting the continuation of the event. With the exception of SH6, all respondents provided more than one reason to explain why the event should continue. SH5 explained their support for the event by emphasizing six benefits, covering benefits to the residents, to the local economy, and to the sponsor. The fact that the event attracts people to the host island was mentioned by most stakeholders. Some stakeholders mentioned both internal benefits (i.e., those that directly benefited them) and external benefits (benefits to other stakeholders), such as SH1, whereas some mainly emphasized internal ones, such as the tourism stakeholders SH3 and SH6.

\section{Event Growth}

Table 4 details the results of the scenarios, with the left column (a) showing what they perceived the event to be and the right column (b) showing what they hoped the event to be in 3 years' time. All

Table 3

Stakeholders' Reason for the Event to Continue

\begin{tabular}{|c|c|c|c|c|c|c|c|}
\hline \multirow[b]{2}{*}{ Reason } & \multicolumn{7}{|c|}{ Stakeholder } \\
\hline & 1 & 2 & 3 & 4 & 5 & 6 & 7 \\
\hline $\begin{array}{l}\text { Community participation and involvement whether it be participating, volunteering, } \\
\text { or spectating }\end{array}$ & $\mathrm{X}$ & $\mathrm{X}$ & & $\mathrm{X}$ & & & \\
\hline Creates a community atmosphere & & & & & & & $\mathrm{X}$ \\
\hline The community likes the event & & & & & $\mathrm{X}$ & & \\
\hline Provides people with something to aim for & $\mathrm{X}$ & & & & & & $\mathrm{X}$ \\
\hline Encourages sport participation & $\mathrm{X}$ & & & & & & \\
\hline Good for the health of the island & & $\mathrm{X}$ & & & $\mathrm{X}$ & & \\
\hline The hosting island once again has its own marathon for local residents to compete in & & & & $\mathrm{X}$ & & & $\mathrm{X}$ \\
\hline Title sponsor benefits from the publicity of the event & & & & & $\mathrm{X}$ & & \\
\hline Brand builder for the title sponsor & & & & & $\mathrm{X}$ & & \\
\hline Raises money for charity & & & & & $\mathrm{X}$ & & \\
\hline Attracts people to the hosting island for the event & $\mathrm{X}$ & $\mathrm{X}$ & $\mathrm{X}$ & & $\mathrm{X}$ & $\mathrm{X}$ & \\
\hline People spend time in the hosting island before and after the event & & & $\mathrm{X}$ & & & & \\
\hline Tourists who have visited for a past event may return to the hosting island for a holiday & & $\mathrm{X}$ & & & & & \\
\hline Promotes the hosting island & $\mathrm{X}$ & & & & & & \\
\hline
\end{tabular}


Table 4

Current (a) and Future (b) Characteristics of the Event

Uncertainties

\begin{tabular}{|c|c|c|c|c|c|c|c|c|c|c|c|c|c|}
\hline \multicolumn{2}{|c|}{1} & \multicolumn{2}{|c|}{2} & \multicolumn{2}{|c|}{3} & \multicolumn{2}{|c|}{4} & \multicolumn{2}{|c|}{5} & \multicolumn{2}{|c|}{6} & \multicolumn{2}{|c|}{7} \\
\hline $\mathrm{a}$ & b & $\mathrm{a}$ & b & $\mathrm{a}$ & b & $\mathrm{a}$ & b & $\mathrm{a}$ & b & $\mathrm{a}$ & $\mathrm{b}$ & $\mathrm{a}$ & b \\
\hline $\mathrm{S}$ & $\mathrm{M}$ & $\mathrm{S}$ & $\mathrm{M}$ & $\mathrm{S}$ & $\mathrm{M}$ & $\mathrm{S}$ & $\mathrm{M}$ & $\mathrm{S}$ & $\mathrm{M}$ & $\mathrm{S}$ & $\mathrm{L}$ & $\mathrm{S}$ & $\mathrm{M}$ \\
\hline $\mathrm{M}$ & $\mathrm{M}$ & $\mathrm{M}$ & $\mathrm{M}$ & $\mathrm{S}$ & $\mathrm{M}$ & $\mathrm{M}$ & $\mathrm{M}$ & $\mathrm{M}$ & $\mathrm{M}$ & $\mathrm{S}$ & $\mathrm{M}$ & $\mathrm{M}$ & $\mathrm{M}$ \\
\hline $\mathrm{S}$ & $\mathrm{M}$ & $\mathrm{S}$ & $\mathrm{M}$ & $\mathrm{S}$ & S & $S$ & $\mathrm{~S}$ & $\mathrm{~S}$ & $\mathrm{~S}$ & $\mathrm{~S}$ & $\mathrm{M}$ & $\mathrm{S}$ & $\mathrm{S}$ \\
\hline $\mathrm{M}$ & $\mathrm{L}$ & $\mathrm{M}$ & $\mathrm{L}$ & $\mathrm{M}$ & $\mathrm{M}$ & $\mathrm{L}$ & $\mathrm{L}$ & $\mathrm{S}$ & $\mathrm{L}$ & $\mathrm{M}$ & $\mathrm{M}$ & $\mathrm{M}$ & $\mathrm{L}$ \\
\hline $\mathrm{S}$ & $\mathrm{L}$ & $\mathrm{S}$ & $\mathrm{L}$ & $\mathrm{S}$ & $\mathrm{M}$ & $\mathrm{M}$ & $\mathrm{L}$ & S & $S$ & $\mathrm{~S}$ & $\mathrm{M}$ & S & $\mathrm{M}$ \\
\hline $\mathrm{S}$ & S & S & $\mathrm{L}$ & $S$ & $\mathrm{M}$ & S & S & $S$ & $S$ & $\mathrm{~S}$ & $\mathrm{M}$ & $\mathrm{S}$ & S \\
\hline $\mathrm{M}$ & $\mathrm{L}$ & S & $\mathrm{M}$ & S & $\mathrm{M}$ & S & $\mathrm{M}$ & $\mathrm{M}$ & $\mathrm{L}$ & $\mathrm{S}$ & $\mathrm{M}$ & $\mathrm{S}$ & $\mathrm{M}$ \\
\hline $\mathrm{M}$ & $\mathrm{M}$ & $\mathrm{S}$ & $\mathrm{L}$ & S & $\mathrm{M}$ & $\mathrm{S}$ & $\mathrm{L}$ & $S$ & $\mathrm{M}$ & $\mathrm{S}$ & $\mathrm{M}$ & $\mathrm{S}$ & $\mathrm{L}$ \\
\hline $\mathrm{S}$ & $\mathrm{M}$ & $\mathrm{S}$ & $\mathrm{L}$ & $S$ & $\mathrm{M}$ & $\mathrm{S}$ & $\mathrm{L}$ & $S$ & $\mathrm{M}$ & $\mathrm{S}$ & $\mathrm{M}$ & $\mathrm{M}$ & $\mathrm{L}$ \\
\hline $\mathrm{M}$ & $\mathrm{M}$ & $\mathrm{S}$ & $\mathrm{M}$ & S & $\mathrm{M}$ & $\mathrm{S}$ & $\mathrm{M}$ & S & $\mathrm{M}$ & $\mathrm{M}$ & $\mathrm{M}$ & $\mathrm{M}$ & $\mathrm{M}$ \\
\hline S & $\mathrm{M}$ & $\mathrm{S}$ & $\mathrm{L}$ & S & $\mathrm{M}$ & $\mathrm{M}$ & $\mathrm{M}$ & $\mathrm{S}$ & $\mathrm{M}$ & $\mathrm{S}$ & $\mathrm{M}$ & $\mathrm{S}$ & $\mathrm{L}$ \\
\hline
\end{tabular}

Amount of participants in the marathon

Amount of participants in the relay race

Amount of participants in the 3k fun run

Mixture of local, national, and/or international participants in the marathon

Mixture of local, national, and international participants in the relay race

Mixture of local, national, and/or international participants in the 3k fun run

Number of spectators physically present on race day

Mixture of local, national, and/or international

spectators physically present on race day

Amount of media coverage in terms of television

Amount of prize money

Level of sponsors of events

Note: For each key uncertainty: (a) a stakeholder's perception of the current size of the event and (b) the vision about what size the event should be in 3 years' time: $\mathrm{S}=$ small; $\mathrm{M}=$ medium; $\mathrm{L}=$ large.

respondents believed that the event should grow in some way (as given by the difference in the indication of small, medium, and large in column b compared to column a). An analysis of the table shows that stakeholders have different perceptions regarding where the event currently was. SH2, SH3, SH5, and SH6 viewed the event as an essentially small one, while SH1, SH4, and SH7 appeared to perceive the event to be of a small to medium size (at least 4 or more of the 11 key uncertainties at the medium level). There were also noticeable differences regarding where the event should be in 3 years' time. SH2, SH4, and SH7 appeared to favor a larger event than the remaining stakeholders.

As far as the specific key uncertainties are concerned, all stakeholders supported growth in the number of marathon runners. The results further suggest that there is more support for certain aspects of running to grow (marathon) than others (3k fun run). Still in relation to the running characteristics of the event, there is a consensus regarding the type of event in relation to the relay race (medium-sized event). In addition, growth also appears to be supported in relation to the number of spectators who physically attend the event. However, some stakeholders favored a mix that involved mainly locals and nationals (SH3, SH5, and SH6), while others aspired for a mix that also involved international spectators (SH2, SH4, and SH7). A similar pattern emerged for the amount of media coverage in terms of television, with some stakeholders being more ambitious than others. These results suggest that organizers of the event will need to reinforce the event as primarily a marathon with events that enable a development process from the competitive relay event rather than a one-off fun run. In terms of spectator base, it will be important to manage the expectations of different stakeholders to ensure that all groups are catered for, so that local and national spectators are not displaced by the economic benefits, desired by some stakeholders, from encouraging a more international tourism base.

\section{The Event Product in 3 Years’ Time}

The last part of understanding the stakeholders' views on what the event should be in 3 years' time involved presenting respondents with a table containing a range of actual and potential event features and asking how they felt about keeping/ adding them to the event by the end of the 3-year period. The results are shown in Table 5. The higher number indicates greater support for the feature. All stakeholders fully supported the continuation of the three races: marathon, relay race, and $3 \mathrm{k}$ fun run. The introduction of other distances was less consensual. While no stakeholder rejected other distances outright (i.e., said “definitely not”), 
Table 5

Race Mix and Additional Features That Could Be Added Over the Next 3 Years

\begin{tabular}{|c|c|c|c|c|c|c|c|}
\hline \multirow[b]{2}{*}{ Event Features } & \multicolumn{7}{|c|}{ Stakeholders } \\
\hline & 1 & 2 & 3 & 4 & 5 & 6 & 7 \\
\hline Marathon* & 4 & 4 & 4 & 4 & 4 & 4 & 4 \\
\hline Relay race* & 4 & 4 & 4 & 4 & 4 & 4 & 4 \\
\hline 3k fun run* & 4 & 4 & 4 & 4 & 4 & 4 & 4 \\
\hline $1 / 2$ marathon & 3 & 3 & 4 & 4 & 4 & 2 & 2 \\
\hline 10k race & 2 & 2 & 3 & 4 & 2 & 3 & 2 \\
\hline $5 \mathrm{k}$ race & 3 & 3 & 4 & 4 & 3 & 2 & 3 \\
\hline Warm-up sessions for the runners before the races begin & 4 & 4 & 4 & 3 & 2 & 4 & 4 \\
\hline $\begin{array}{l}\text { An exercise class held in the Marathon Village for anyone to participate } \\
\text { in while waiting for the first marathon runner to cross the finish line }\end{array}$ & 3 & 3 & 4 & 2 & 2 & 3 & 3 \\
\hline Live music performances of a variety of genre & 4 & 3 & 4 & 3 & 3 & 3 & 4 \\
\hline Fairground rides and stalls & 2 & 3 & 2 & 2 & 2 & 2 & 2 \\
\hline Food and beverage stalls offering a variety of cuisines & 4 & 4 & 4 & 4 & 4 & 4 & 4 \\
\hline $\begin{array}{l}\text { An area in the Marathon Village for local sport shops such as Wheways and } \\
\text { sport brands such as Nike to showcase and sell their products and services }\end{array}$ & 3 & 4 & 3 & 4 & 3 & 4 & 3 \\
\hline $\begin{array}{l}\text { An area in the Marathon Village for sport brands to showcase and sell } \\
\text { their products and services }\end{array}$ & 3 & 4 & 3 & 4 & 3 & 4 & 3 \\
\hline $\begin{array}{l}\text { Exhibition that runs for } 1 \text { or } 2 \text { days before race day. This could be the location } \\
\text { where the runners collect their race packs and ask questions. Organizations that } \\
\text { could feature at the exhibition are local sport shops, sport brands, sport } \\
\text { nutritionalists/physiotherapists offering advice, mainly benefiting charities of the event }\end{array}$ & 3 & 4 & 4 & 3 & 4 & 4 & 3 \\
\hline $\begin{array}{l}\text { An after party on the evening of race day for people such as the runners, } \\
\text { their supporters, and the volunteers }\end{array}$ & 4 & 4 & 4 & 5 & 2 & 4 & 4 \\
\hline
\end{tabular}

Note: The different numbers represent the stakeholders' level of agreement with the race mix and additional features of the event in 3 years' time: 4 = definitely yes; 3 = probably yes; 2 = probably no; 1 = definitely no.

*Current event features.

there was less support for the inclusion of different distances. The $5 \mathrm{k}$ and $10 \mathrm{k}$ races received little support from a majority of stakeholders, while the $1 / 2$ marathon received contradictory support. Five of the seven stakeholders appeared to support it (i.e., yes), while two stakeholders appear not to support it (SH6 and SH7).

Interviewees were also asked to explain why they preferred the race mix that they described. The lack of support for including new races was usually explained by the logistic requirements that this could involve. In addition, interviewees pointed out that it was uncertain that more participants would be attracted by adding more races. Increasing the number of races without growing the number of participants would lead to fewer people participating in each race as they would be spread through different distances. These diverted and substitute demand concerns focused on impacts within the races offered at this event (people who currently run the $3 \mathrm{k}$ fun run moving to the $5 \mathrm{k}$ ) or the impacts on other different events taking place in the hosting island (they already have a $10 \mathrm{k}$, so a new one was not needed). One stakeholder argued that no change was required because a niche had been carved (with the three existing races), and therefore, the event should stick with the existing product, although they had earlier argued for market growth. The stakeholder who was least supportive of new races (SH7) mentioned that their opinion could be subject to change if the need for additional races was to be demonstrated, thus keeping an open mind regarding the issue. Support for the new distances was based on their ability to appeal to a different group of people. A different stakeholder acknowledged that all offered races could be included. However, they emphasized that this would require a longer event (i.e., a weekend) to accommodate all the races.

As far as the nonrunning features of the event are concerned, the results indicate that there was good support for new components to be added. However, some stakeholders were more supportive than others. For example, SH2, SH3, and SH5 fully supported the introduction of the majority of 
the features suggested, while the remaining stakeholders appeared to be less certain of their support for the inclusion of new features. SH5 was not particularly supportive of the introduction of four of the nine nonrace features. Table 5 also illustrates which features were least and more supported. The least supported feature was the introduction of fairground rides and stalls (six of the seven stakeholders answered probably not), while food and beverage stalls offering a variety of cuisines were fully supported by all stakeholders.

\section{Discussion, Conclusions, and Implications}

The resources and contributions required to successfully run an event in the long term require the involvement, cooperation, and goodwill of different stakeholders (Getz at al., 2010). These stakeholders are often associated with the event for different reasons, which results in different (and potentially conflicting) views regarding how the event should be run, notably the format of the event. Hence, it is important to monitor and review activities to detect problems and act to prevent damage to stakeholder relationships (O’Sullivan \& Jackson, 2002), which could jeopardize the sustainability of the event. Ryan (2002) further highlighted this by arguing that not only should stakeholders be identified but nurturing relationships with them and between them should also be a key management endeavor. This research investigated whether the stakeholders of an event wanted it to grow, and if so, what characteristics are needed to be considered as part of that growth. Not only the level of growth desired was investigated, but the research also examined whether there was agreement in relation to the characteristics of the product in the following 3 years.

The overall conclusion of this research was that all stakeholders wanted the event to continue and grow. While all stakeholders supported the continuation of the event, it has been made apparent that each stakeholder had their own reasons for the event to continue, which are influenced by their backgrounds. SH3's and SH6's reasons for supporting the event were focused on attracting tourists. This is not surprising because they both worked within the hospitality and tourism industries in the island. Alternatively, SH7, who represents past runners, provided reasons that are centered on their passion for running. SH4 (association of volunteers) works within the community, which was reflected in their identifying mainly community objectives. SH1, SH2, and SH5 saw the "bigger picture," recognizing four to five different reasons. Crespi-Vallbona and Richards (2007) would recognize this as being more strategic and instrumental because of the stakeholders' involvement in policy making and their distance from the production of the event itself. The different agendas of the various stakeholders make it clear that, in the case of community-based events such as the one studied here, the path toward legitimation alluded by Getz et al. (2007) is a difficult one, as it involves striking a fine balance between not only a wide array of stakeholders' objectives but also stakeholders with fairly specific or broader perspectives on the roles played by the event. Understanding the different agendas of the various stakeholders is, thus, a first and critical step in making sure that, over time, the chosen legitimization path reflects the various agendas.

Another key finding of the study was the differences in the views of how growth should be achieved, both in the number and type of participants and spectators and product features. The views of the different stakeholders can be directly related to who they are in terms of their stake in the event and, therefore, their objectives for the event itself. Unsurprisingly, the economic stakeholders, mainly represented by tourism and hospitality representatives, tended to desire a more ambitious event, whereas those from a sport or community background appear to favor a smaller event, with a strong sport component involving mainly the local community. These differing interests, as explained by Larson and Wikström (2001), can lead to conflict, which, in turn, can affect the event's success (Abma, 2000).

According to literature (Larson \& Wikström, 2001), conflict would most likely have occurred because of these differing interests. Yet, to date, the event has been successful regardless of the stakeholders' differing interests. One possible explanation is that the stakeholders' initial involvement was based on the agreement that the event would start as a small, island-oriented event, a feature that, 3 years on, was still maintained to a large extent. However, after the initial success, some stakeholders may 
have developed a desire for the event to take on a different course so that they could accrue greater benefits. In this instance, the economic stakeholders may have developed, over time, the view that the event provided an opportunity for greater economic returns to the tourism and hospitality industries by attracting more participants from outside the island. Thus, the consensus that underpinned the creation of the event has the potential to evolve toward a more conflicting relationship due to the development of incompatible objectives (Larson \& Wikström, 2001; Reid, 2011).

Over time, especially if growth is pursued, it is also possible that the relative power of stakeholders may change. In this context, what is important is to ensure that certain stakeholders do not take on a dominant role over strategic decisions such as the size and features of the event. If tourism stakeholders (e.g., the tourist board or tourism associations) were to take on a leading role in managing the event and if the agenda of tourism stakeholders (usually bigger event) is pressed ahead, this could bring problems in terms of stakeholder disengagement and conflict. If vigorous growth is pursued, tensions could increase, leading to extreme positions. In such circumstances, the event starts to become less acceptable in the eyes of some groups within the community, leading to difficulties in managing the different perspectives (Burns \& Howard, 2003), thus affecting the path toward legitimization negatively (Getz et al., 2007). The continuing legitimization of the event will require managing the apparent differences in objectives and vision between the tourism/economic stakeholders and the sport/community ones. The management structures put in place, which will be among the most important management decisions, should be designed in a way that the views of all relevant stakeholders are taken into consideration.

\section{Implications for Practice}

Based on the findings of the study, it is possible to make appropriate recommendations to decisionmakers with regard to whether the event should grow and the shape and pace of that growth. The methods applied in this research demonstrate how views of different stakeholders could be elicited through a potentially more democratic process than round-table meetings where results are more dependent on negotiation skills or dealing with stakeholders where the power influence becomes more significant. It may be the first stage of achieving mutual commitment (Larson \& Wikström, 2001), which is when the stakeholders strive to find agreement that represents all stakeholders rather than the most dominant ones. By identifying issues ex ante, appropriate action can be taken so that those differences are actively managed. This, in turn, contributes to adopting proactive rather than reactive stakeholder management.

\section{Implications for Future Research and Theoretical Developments}

The significance of this research lies in furthering our understanding of events management and more specifically that of the strategic development of events. With further research, it could be found that events have a more unique setting than that of the traditional "firm in society" basis that began the stakeholder theory. This research demonstrates an original methodology in engaging stakeholders in the process of strategic decision making in deciding whether and how an event should develop in the future. It emphasizes the importance of conducting an ex ante evaluation of the growth of an event that incorporates the views of different stakeholders. Understanding why stakeholders think a particular event should be organized is part of the process of identifying the potential stakeholders but not necessarily the legitimacy and specific stakes they have in the event. It does, however, help to understand the stakeholders' view of the objectives for the event. From this, the event organizers can better understand the dynamics between stakeholders as illustrated by the tables that reported feedback from them, whether solicited through open-ended questions or the structured process of the scenario options.

Future research could go beyond the stages identified by Shoemaker (1995) and adapted in this research. The methodology presented in this research provides a simple yet effective way of identifying individual stakeholder perspectives. Once stakeholders' event objectives and their views 
for growth are identified, one needs to know how to agree upon and implement a future vision for the event. In this research, the diversity of stakeholder interests and their views for the future of the event have been elicited. A future scenario can be devised from the results, and potential contentious issues are identified. What has not been resolved is how these can be best managed. Presumably, management of stakeholder relationships should take the form of a multilateral consultative process (Ryan, 2002). Future studies could complement the assessment of individual perspectives by incorporating the group interaction/consultative element, especially when the assessment of individual stakeholders' views suggests conflicting perspectives.

Another area of future research involves examining the stability of stakeholders' objectives and vision over time. Stakeholders are usually represented, formally or informally, by an individual or a small group of individuals. Future research could examine how changes in the leadership composition of stakeholders affect their objectives and vision for and the level of interest in the event. In this study, the key uncertainties about the future of the event focused on the product attributes of the event. Future research could examine other types of uncertainties, such as the various objectives the event should fulfill.

This research examined the views of 7 of the 25 event stakeholders. These are among the most relevant as given by the high power and/or interest in the event. Needless to say, a more accurate picture about the future of the event can be achieved by including in the study a broader range of stakeholders. The results of this research could also form the content for a broader stakeholder quantitative survey that could include samples of businesses, residents, participants, and spectators of the event, instead of their representatives, as was the case in this research.

It is not surprising that managing event stakeholders has become a key feature of event management (Buch et al., 2011; Getz, 2007; Reid, 2011). While interest in stakeholder management research has grown in recent years, at present, much of the existing work in the area is of a conceptual nature. Thus, methodologies that could help implement stakeholder management principles are welcome. Using scenario planning and the stakeholder theory, the need to develop prospective methodologies (i.e., to anticipate issues rather than react to them) has been emphasized in this research.

\section{References}

Abma, T. A. (2000). Stakeholder conflict: A case study. Evaluation and Programme Planning, 23(2), 199-210.

Ansoff, H. I. (1956). Corporate strategy. New York: McGraw-Hill.

Bowdin, G., Allen, J., O’Toole, W., Harris, R., \& McDonnell, I. (2008). Events management (3rd ed.). Oxford: Elsevier Butterworth-Heinemann.

Buch, T., Milne, S., \& Dickson, G. (2011). Management multiple stakeholder perspectives on cultural events: Auckland's Pasifika Festival. Journal of Hospitality Marketing \& Management, 20, 311-328.

Burns, G., \& Howard, P. (2003). When wildlife tourism goes wrong: A case study of stakeholder and management issues regarding Dingoes on Fraser Island, Australia. Tourism Management, 24(6), 699-712.

CityLocal. (2009). Beach break St. Agnes-Cancelled. Retrieved January 16, 2012, from http://www.citylocal. co.uk/Carrick/news-in-Carrick/beach-break-st-agnescancelled-40662/

Crespi-Vallbona, M., \& Richards, G. (2007). The meaning of cultural festivals: Stakeholder perspectives in Catalunya. International Journal of Cultural Policy, 13(1), 103-122.

Cymbalista-Clapp, J. (2011). Following police complaint, New Quebec Federation's Amateur Event cancelled. Top MMA News. Retrieved February 1, 2012, from http:// topmmanews.com/2012/01/27/following-police-complaintnew-quebec-federation\%E2\%80\%99s-amateur-eventcancelled/

Derrett, R. (2004). Festivals, events and the destination. In I. Yeoman, M. Robertson, J. Ali-Knight, S. Drummond, \& U. McMahon-Beattie (Eds.), Festival and events management. An international arts and culture perspective (pp. 32-50). Oxford: Elsevier Butterworth-Heinemann.

Endley, B. (2011). Lingfield Park Racecourse cancels firework display. Get Surrey. Retrieved January 15, 2012, from http://www.getsurrey.co.uk/news/s/2101951 lingfield park racecourse cancels firework display

Ferrand, A., \& McCarthy, S. (2009). Marketing the sports organisation: Building networks and relationships. Abingdon: Routledge.

Fletcher, A., Guthrie, J., Steane, P., Roos, G., \& Pike, S. (2003). Mapping stakeholder perception for a third sector organisation. Journal of Intellectual Capital, 4(4), 505-527.

Freeman, R. E. (1984). Strategic management: A stakeholder approach. Boston: Pitman.

Friedman, A. L., \& Miles, S. (2002). Developing stakeholder theory. Journal of Management Studies, 39(1), 1-21.

Getz, D. (2007). Event studies. Theory, research and policy for planned events. Oxford: Butterworth-Heinemann. 
Getz, D. (2008). Event tourism: Definition, evolution, and research. Tourism Management, 29(3) 403-428.

Getz, D., \& Andersson, T. (2009). Sustainable festivals: On becoming an institution. Event Management, 12, 1-17.

Getz, D., Andersson, T., \& Carlsen, J. (2010). Festival management studies: Developing a framework and priorities for comparative and cross-cultural research. International Journal of Event and Festival Management, 1(1), 29-59.

Getz, D., Andersson, T., \& Larson, M. (2007). Festival stakeholder roles: Concepts and case studies. Event Management, 10(2/3), 103-122.

Goldblatt, J. (2008). Special events: The roots and wings of celebration (5th ed.). New Jersey: Wiley.

Goldblatt, J., \& Nelson, K. S. (2001). The international dictionary of event management (2nd ed.). Canada: John Wiley \& Sons.

Gummesson, E. (2000). Qualitative methods in management research (2nd ed.). London: Sage.

Jennings, G. (2001). Tourism research. Australia: John Wiley \& Sons.

Johnson, G., Scholes, K., \& Whittington, R. (2005). Exploring corporate strategy. Essex: Pearson Education.

Karlsen, S., \& Nordström, C. (2009). Festivals in the Barents Region: Exploring festival-stakeholder cooperation. Scandinavian Journal of Hospitality and Tourism, 9(2-3), 130-145.

Larson, M. (2009). Festival innovation: Complex and dynamic network interaction. Scandinavian Journal of Hospitality and Tourism, 9(2/3), 288-307.

Larson, M., \& Wikström, E. (2001). Organising events: Managing conflict and consensus in a political market square. Event Management, 7(1), 3-22.

Limerick, D., Cunnington, B., \& Crowther, F. (2002). Managing the new organisation: Collaboration and sustainability in the postcorporate world (2nd ed.). London: Allen \& Unwin.

Mallen, C., \& Adams, L. J. (2008). Sport, recreation and tourism event management: Theoretical and practical dimensions. Oxford: Elsevier Butterworth-Heinemann.
Miles, M. B., \& Huberman, A. M. (1994). An expanded sourcebook, qualitative data analysis (2nd ed.). London: Sage.

Mitchell, R. K., Agle, B. R., \& Wood, D. J. (1997). Toward a theory of stakeholder identification and salience: Defining the principle of who and what really counts. The Academy of Management Review, 22(4), 853-886.

Murphy, B., Maguiness, P., Pescott, C., Wislang, S., Ma, J., \& Wang, R. (2005). Stakeholder perceptions presage holistic stakeholder relationship marketing performance. European Journal of Marketing, 39(9-10), 1049-1059.

O’Sullivan, D., \& Jackson, M. (2002). Festival tourism: A contributor to sustainable local economic development? Journal of Sustainable Tourism, 10(4), 325-342.

Reid, S. (2011). Event stakeholder management: Developing sustainable rural event practices. International Journal of Event and Festival Management, 2(1), 20-36.

Reid, S., \& Arcodia, C. (2002). Understanding the role of the stakeholder in event management. Paper presented at the Events and Placemaking Conference, Sydney, Australia.

Ryan, C. (2002). Equity, management, power sharing and sustainability-Issues of the "new tourism." Tourism Management, 23, 17-26.

Shoemaker, P. J. H. (1995). Scenario planning: A tool for strategic thinking. Sloan Management Review, 6(2), 25-40.

Toor, S., \& Ogunlana, S. (2010). Beyond the "iron triangle": Stakeholder perception of key performance indicators (KPIs) for large-scale public sector development projects. International Journal of Project Management, 28, 228-236.

Westerbeek, H., Smith, A., Turner, P., Emery, P., Green, C., \& van Leeuwen, L. (2006). Managing sport facilities and major events. Abingdon: Routledge.

Wheeler, D., \& Sillanpaa, M. (1997). The stakeholder corporation. London: Pitman Publishing.

Yeoman, I., \& McMahon-Beattie, U. (2005). Developing a scenario planning process using a blank piece of paper. Tourism and Hospitality Research, 5(3), 273-285. 